\title{
O Ocaso da Utopia Telecomunicacional: regular para quem no tocante ao Direito Fundamental à Privacidade?
}

The End of Telecommunications Utopia: Regulate to Whom on the Fundamental Right of Privacy?

Veil after veil will lift - but there must be Veil upon veil behind.

(The Light of Asia, Livro VIII)

Edwin Arnold, 1832-1904.

\begin{abstract}
Resumo
O presente estudo figura como introdução à Revista de Direito, Estado $e$ Telecomunicações do Grupo de Estudos em Direito das Telecomunicações da Universidade de Brasília, abordando sinteticamente a estrutura, conteúdo e política editorial da revista. Em acréscimo, o texto analisa os principais acontecimentos do setor no Brasil, bem como normas e julgados relativos ao ano de 2013, para registro das principais discussões político-jurídicas do setor de telecomunicações brasileiro referentes ao ano anterior ao da publicação.
\end{abstract}

\section{Abstract}

The article introduces this issue of the Law, State, and Telecommunications Review by way of presenting its contents. Statutes and the administrative regulation of 2013 pertaining to telecommunications are referred to in detail. It also addresses the main political and juridical discussions on the Brazilian telecommunications sector that took place the year before the publication of the journal's current volume.

\section{Apresentação}

Em consonância com o propósito inaugural da Revista de Direito, Estado e Telecomunicações, apresenta-se o sexto volume da publicação segundo o formato que se segue, mantendo-se a perspectiva de consolidação da revista como um instrumento de pesquisa jurídica setorial.

Para tanto, a presente introdução vai além da identificação das temáticas constantes da publicação e dá sequência ao registro histórico do arcabouço normativo setorial e do correspondente contexto socioeconômico e político das telecomunicações no Brasil. $\mathrm{O}$ artigo introdutório também registra as principais discussões jurídico-regulatórias que marcaram o ano de 2013. 
$\mathrm{O}$ artigo seguinte consiste em estudo promovido pelo Centro Berkman para Internet e Sociedade, da Universidade de Harvard, que, na linha do direito à comunicação na internet, evidencia as condições de manifestação do pensamento no âmbito da rede mundial de computadores em solo Russo. Partindo-se do pressuposto de que a mídia tradicional russa - leia-se radiodifusão e imprensa, em especial os canais federais de televisão - tem perdido muito de sua autonomia, os pesquisadores de Harvard avaliam o desenvolvimento e a evolução da esfera pública conectada russa como alternativa à discussão de questões sociopolíticas obstaculizada no espaço midiático offline. $\mathrm{O}$ estudo, portanto, traz à tona o papel desempenhado pelo espaço midiático online de espaço público alternativo à mídia tradicional para fins de participação cívica. Dentre os achados do estudo, estão a emergência de uma esfera pública interconectada vibrante e diversa, o uso crescente de plataformas digitais na mobilização social e na ação cívica, e a persistente qualidade da internet russa como ambiente aberto e livre a despeito de ataques de negação de serviço orquestrados e perseguição de jornalistas críticos ao Governo e a grandes empreendimentos econômicos.

O segundo artigo de Peng Hwa Ang e Natalie Pang enfrenta a questão tão em voga da globalização da internet com enfoque na dimensão institucional do Fórum de Governança da Internet e do trilema globalização, soberania e democracia. Nele, são esboçados cenários de apresentação de uma globalização "contida" da internet para preservação de dimensões soberanas e democráticas de Estados nacionais. Trata-se de um artigo relevante, pois, para além de situar o tema da governança da internet em sede teórica de relação entre soberania e democracia, o situa a partir de casos concretos e demonstra como tais experiências se encaixam na lógica da ação coletiva.

Ronaldo Bach, por sua vez, em artigo intitulado Regulação da Guerra Cibernética e o Estado Democrático de Direito no Brasil traz à tona a discussão ainda incipiente no Brasil sobre a dimensão regulatória da defesa eletrônica e cibernética. $\mathrm{O}$ estudo é esclarecedor da guerra cibernética em sua relação teórica com o Estado Regulador e os direitos fundamentais. Nesse ponto, o autor introduz novidade de análise ao elevar a discussão das opções políticas de guerra cibernética a componentes do Estado Regulador, como instrumento que responde a um vácuo regulatório de disciplina internacional. 
Em artigo de temática correlata ao anterior, o estudo de Rodrigo Silva Chaves intitulado "o papel do Ministério da Defesa no processo de integração e de regulação das comunicações militares no Brasil" aprofunda a disciplina jurídico-política dessa espécie comunicacional a partir de análise da estrutura institucional hoje segmentada nas Forças singulares no tocante ao campo das comunicações militares e da ausente padronização de requisitos técnicos do processo de aquisição de equipamentos e sistemas correspondentes.

O artigo seguinte, de Isaac Calaça, enfrenta a questão da apresentação renovada do direito à intimidade no ambiente cibernético, em especial a conformação social do direito à autodeterminação dos fluxos de informação.

Ao artigo intitulado "Imunidade antitruste às ações governamentais no contexto da desregulação do setor de telecomunicações: uma análise a partir do julgamento do caso VU-M pelo CADE", de autoria de Deborah Batista Caixeta, coube o aprofundamento dos limites de atuação da regulação geral de matiz concorrencial do CADE frente à regulação setorial técnica da ANATEL a partir da análise dos argumentos do caso VU-M em batimento com a teoria da ação governamental - State Action Doctrine -, a teoria do interesse público e a teoria da escolha pública - public choice.

$\mathrm{O}$ histórico da classificação jurídica do espectro de radiofrequências precede a análise de Guilherme Pereira Pinheiro sobre a aplicabilidade da teoria processual administrativa da regulação na regulação desse bem público no artigo intitulado "A Teoria Processual Administrativa Aplicada à Regulação do Espectro Radioelétrico".

Finalmente, o artigo de Rafael da Silva Santiago aborda detalhadamente a prática institucional da ANATEL na solução de disputas, catalogando as atividades de sua competência previstas no art. 19 da Lei Geral de Telecomunicações como afetas ou não à arbitralidade objetiva.

Segue-se, na última seção da revista, a reunião das normas do setor de telecomunicações do ano de 2013 organizadas por temas e referenciadas a tabelas informativas. Ao final, foi inserido um exaustivo índice alfabético e remissivo das normas do setor no ano de 2013. Cada tema presente em dita seção contém referências a normas de todos os níveis e a atos administrativos correlatos. 


\section{O setor de telecomunicações no ano de 2013}

O ano de 2013 foi um ano especial para o setor de telecomunicações, como ano debutante dos 15 anos de existência da ANATEL; um ano de enfrentamento de questões regulatórias sob um enfoque amadurecido. ${ }^{1}$

\section{Conflito de competências federativas sobre antenas e a disputa pela faixa de $700 \mathrm{MHz}$}

Talvez o último problema da velha guarda regulatória enfrentado pela ANATEL tenha dito respeito às dificuldades de expansão de infraestrutura de antenas para o Serviço Móvel Pessoal sob pressão nas cidades-sede da Copa das Confederações, da Copa do Mundo de 2014 e das Olimpíadas de 2016. Embora não dependesse de uma mudança regulatória da ANATEL, mas de leis municipais disciplinadoras de disposição urbana, meio-ambiente e consumidor, o evento mais relevante do setor em termos de abertura do ano de planejamento de atuação regulatória em Brasília - o Seminário Política de (Tele)Comunicações de fevereiro de 2013 - girou em torno de dois pontos centrais de atuação da ANATEL: a demanda das operadoras de Serviço Móvel Pessoal (SMP) por uma atuação pró-ativa nos municípios para convencimento das autoridades a relaxarem os requisitos impeditivos da instalação de novas antenas e as demandas divergentes dos setores de radiodifusão e de SMP e infraestrutura móvel sobre estudos de disponibilidade de espectro para ingresso do celular de quarta geração (4G) na faixa de $700 \mathrm{MHz}$ a ser liberada quando do encerramento da agenda de digitalização da radiodifusão terrestre.

No início de 2013, vozes do Ministério das Comunicações e da ANATEL confirmaram a intenção de desligamento do sinal analógico de TV aberta terrestre de forma progressiva, iniciando-se em 2015, com projeção de encerramento postergada para 2018, em expressa acomodação planejamento original de desligamento completo dos sinais em 2016. A discussão política travada em 2013 concentrou-se em torno de estudos técnicos de grupo ministerial com apoio da ANATEL pró introdução plena do $4 \mathrm{G}$ inclusive em grandes centros metropolitanos, alegando a

${ }^{1} \mathrm{O}$ capítulo do setor de telecomunicações no ano de 2013 foi elaborado por Márcio Iorio Aranha. 
possibilidade de ajustes de engenharia que eliminariam interferências prejudiciais no serviço de radiodifusão digital terrestre, enquanto, de outro lado, estudos técnicos contratados pela Associação Brasileira de Emissoras de Rádio e Televisão (ABERT) e desenvolvidos pela Sociedade Brasileira de Engenharia de Televisão (SET) apontavam no caminho contrário de inviabilidade de introdução do 4G na faixa de $700 \mathrm{MHz}$ sob pena de prejuízo à recepção do serviço de radiodifusão em grandes centros metropolitanos e principais mercados de telecomunicações.

Em fevereiro de 2013, foi anunciada a antecipação da licitação da frequência de $700 \mathrm{MHz}$ para o $4 \mathrm{G}$, mais cobiçada que a de $2,5 \mathrm{GHz}$, que fora licitada em junho de 2012 por US\$ 2,9 bilhões, por possuir maior alcance e, consequentemente, demandar um menor número de antenas. A expectativa divulgada à imprensa no início de 2013 era de que a licitação rendesse cerca de US\$ 40 bilhões, segundo relatório da representação de comércio dos Estados Unidos, que questionava a exigência de percentual de fabricação nacional de equipamentos dos vencedores das licitações. Anunciava-se a edição próxima de portaria do Ministério das Comunicações para liberação antecipada dos canais 51 a 69 UHF, inicialmente prevista para 2016, que fora a previsão regulamentar do processo de introdução da TV digital terrestre no Brasil. Já no anúncio governamental de início de fevereiro de 2013, que sucedeu a encontro com representantes das radiofusoras no semana anterior, antecipou-se que estaria sendo estudada uma compensação às empresas de radiodifusão pela entrega antecipada das frequências às telecomunicações, mediante, por exemplo, o custeio pelas operadoras de SMP vencedoras das licitações do valor gasto com a digitalização dos canais de TV realocados. A compensação foi solenemente afastada pela ANATEL, declarando-se ausência de política pública nesse sentido.

Em 28 de fevereiro de 2013, a ANATEL lançou consulta pública com a proposta de regulamento sobre condições de uso de radiofrequências na faixa de $698 \mathrm{MHz}$ a $806 \mathrm{MHz}$ com a especificação da destinação da faixa de $700 \mathrm{MHz}$ para o LTE (4G).

Não tardou para que, em audiência pública, atores setoriais da área de segurança pública e militar solicitassem a reserva de $5 \mathrm{MHz}+5 \mathrm{MHz}$ para comunicação das polícias de segurança e $10 \mathrm{MHz}+10 \mathrm{MHz}$ para operações sociais de distribuição de alimentos, água e segurança interna do Exército, 
contrapondo-se o interesse comercial ao da segurança e serviços de utilidade pública demandados pela população. Como se verá mais adiante, a demanda foi exitosa em parte.

Pela primeira vez, a discussão pública sobre a transição para a TV digital via desligamento programado para se iniciar em março de 2015, por Brasília, seguindo-se São Paulo, em abril, e Rio de Janeiro, em maio, com previsão de desligamento de todas as capitais para 2015 e de todo o país para 2018, resultou em enfrentamento do que fazer com aqueles que não tiverem condições de migrar por si sós. Foi suscitado, durante o ano de 2013, por exemplo, o financiamento dos aparelhos conversores para a população de baixa renda via inclusão da TV Digital na listagem de produtos passíveis de aquisição mediante financiamento do programa "Caixa Móveis" para beneficiários do bolsa família. O mercado vindouro da TV digital, como ocorreu nos países que já realizaram o desligamento analógico, deverá ser, em parte, viabilizado com subsídios governamentais.

Em outra esfera de expansão celular de $4^{a}$ geração, agora na frequência de $2,5 \mathrm{GHz}$, em $1^{\circ}$ de julho de 2013 , passou a ser exigido das operadoras de MMDS que ocupavam os $190 \mathrm{MHz}$ da faixa de 2,5 GHz a se restringirem a um bloco de $50 \mathrm{MHz}(2.570 \mathrm{MHz}$ a $2.620 \mathrm{MHz}$ ), algo previsto desde 2010, na Resolução ANATEL no 544, mas finalmente implementado em 2013 após intensas negociações em especial no tocante à fixação do valor de indenização pela abertura de espectro para as operadoras de Serviço Móvel Pessoal (SMP) e Serviço de Comunicação Multimídia (SCM).

Em maio de 2013 foi publicada a resolução de arbitragem da ANATEL sobre o montante de indenização das empresas de telecomunicações vencedoras do leilão das faixas de $2,5 \mathrm{GHz}$ para as empresas do serviço de MMDS até então ocupantes da faixa, fixado o valor de R 314 milhões, conforme o critério da base de usuários de MMDS em agosto de 2010 e o custo estimado de migração das bases legadas para outras plataformas similares de TV a Cabo ou DTH, ou mesmo de substituição de infraestrutura do MMDS por serviço de banda larga via tecnologia TD-LTE. Os valores foram distribuídos entre Acom, Telefônica, MMDSC, Net Serviços, TV Show, Ibituruna, Sunrise, Teleserv, Sercomtel, Bahiasat, Jangadeiro, VerTV, TV Filme, entre outras partícipes do mercado em extinção do serviço de MMDS. 


\section{O setor de telecomunicações frente ao movimento popular de 2013}

A revolta popular que se instaurou inicialmente em São Paulo contra a elevação das tarifas de ônibus em junho de 2013 logo se alastrou por todo o país via redes sociais contra a corrupção, a Proposta de Emenda à Constituição $n^{\circ} 37$ (PEC 37), que pretendia retirar poderes investigatórios do Ministério Público, mantendo-os exclusivamente na corporação policial, bem como inúmeras outras demandas de ordem social, tais como maiores investimentos em saúde e educação públicas, vieram em meio ao visível volume de gastos expendidos nos estádios de futebol para a Copa das Confederações em 2013 e para a Copa do Mundo em 2014.

O setor de telecomunicações passou despercebido no início da movimentação popular, mas a reação a aumentos planejados de energia, fornecimento de água e transportes fez com que todos eles fossem adiados, afetando, evidentemente, as demais tarifas controladas e deixando a ANATEL em situação delicada para autorização de reajustes para o ano seguinte, ou mesmo, anúncio de liberação de controle tarifário para chamadas internacionais. O setor, entretanto, passou ao largo da crise política. Na mesma toada, o momento de reação ao descontrole público sobre os benefícios de ordem social de serviços públicos levou à concentração de atenções sobre projetos de lei em andamento no Congresso Nacional, em especial, o PL 4330/2004, que visava facilitar a realização de contratos de terceirização em geral que afetariam as empresas de telecomunicações no uso de serviços terceirizados de atendimento e instalação sem que sofressem o risco de serem responsabilizadas por débitos trabalhistas deles decorrentes. Apesar de reativada sua tramitação paralisada desde 2011, via discussão na Comissão de Constituição, de Justiça e de Cidadania (CCJC) da Câmara dos Deputados, não foi à plenário em 2013.

Os serviços de telefonia e banda larga não foram objeto das críticas de milhares de manifestantes nas principais capitais do país, que se concentraram, então, na elevação realizada ou programada de tarifas de ônibus e na deficiência dos serviços públicos de saúde e educação fundamental e média, levando à implementação de programas federais, estaduais e municipais de reestruturação da infraestrutura de transportes terrestres.

O Programa Nacional de Banda Larga, de 2010, antecipou o esforço governamental às manifestações de 2013 ao revelar um governo pró-ativo 
de regulação da universalização do acesso à banda larga. Os protestos populares exigindo o fim da corrupção, o incremento de serviços públicos de qualidade então focados em transportes terrestres, saúde e educação, deixaram o setor de telecomunicações invisível às críticas de elevadas tarifas e preços segundo critérios comparativos internacionais.

Não passou despercebido, entretanto, o robustecimento do setor de TV por assinatura após sua abertura viabilizada pela lei de comunicação audivisual de acesso condicionado (Lei 12.485/2011 - Lei do SeAC) ao ser aprovado, em dezembro de 2013, na Comissão de Ciência, Tecnologia, Inovação, Comunicação e Informática (CCT), do Senado Federal, projeto de lei que estabelece pena de seis meses a dois anos de prisão para o crime de interceptação ou receptação não autorizada de sinais de TV por assinatura (PLS 186/2013), prática vulgarmente apelidada de "gatonet" em analogia à prática de "gato" - ligação não autorizada - da rede de energia elétrica.

\section{O caso Snowden e Miranda}

A geopolítica telecomunicacional, por sua vez, sofreu uma guinada por escândalos de vazamento de práticas do serviço secreto de informações dos EUA, capitaneado pelo foragido terceirizado de sua agência de inteligência, Edward Snowden, que revelara a quebra de sigilo de ligações telefônicas e troca de informações via redes da Verizon e de dados da Google e outras empresas da internet, minando a confiança sobre a privacidade e segurança das redes de telecomunicações, inclusive entre os EUA e seus aliados europeus.

Os investimentos na infraestrutura de banda larga e sua inteligência de rede passaram a servir como índice da nova geopolítica mundial de países desenvolvidos da sociedade-rede, com investimentos conjuntos nipoeuropeus de um lado, e de países periféricos com seus sistemas relativamente isolados, como a China e demais países à procura de uma espaço ao sol no mundo da informação, de outro, tendo-se reservado aos Estados Unidos uma posição singular de inaugurador e hospedeiro da regulação da internet, sob crescente desconfiança dos demais.

Mesmo as manifestações populares ocorridas no Brasil em 2013 não tiveram o efeito persistente da crise de confiança gerada pelo vazamento de informações daquele empregado terceirizado do serviço de informações dos Estados Unidos da América - Edward Snowden - sobre práticas 
corriqueiras de filtragem de dados de milhões de usuários de telefonia e de internet dos Estados Unidos e de outros países. A par da crise política gerada pelo aceite do pedido de asilo provisório de Edward Snowden na Rússia em meio à ameaça de intervenção militar norte-americana e de seus aliados na Síria, país com intensos laços comerciais e militares com a Rússia, outro evento subsequente garantiu a centralidade do tema na agenda política internacional de 2013: a detenção de um brasileiro ligado ao jornal The Guardian no aeroporto de Londres com base em lei antiterrorismo inglesa para fins de confisco de material presumivelmente ligado ao vazamento de informações de Edward Snowden.

Em 18 de agosto de 2013, no aeroporto internacional de Heathrow, em Londres, um brasileiro chamado David Miranda foi detido pela polícia inglesa por 8 horas e 55 minutos para interrogatório com base na lei antiterrorismo daquele país. O Terrorism Act 2000 fora instituído pelo parlamento inglês com o objetivo de política legislativa para facilitar a detenção de pessoas originárias ou ligadas a movimentos terroristas da Irlanda do Norte, abrindo espaço para que pessoas pudessem ser provisoriamente detidas para questionamento independentemente de fundada suspeita para interrogatório pelo prazo máximo de 9 horas.

David Miranda dirigia-se a Londres para se encontrar com seu parceiro jornalístico - Glenn Greenwald - com o fito de, presumivelmente, entregarlhe documentos obtidos de fontes norte-americanas sobre o vazamento de informações de invasão de ligações telefônicas e contatos eletrônicos por parte do governo norte-americano.

O governo norte-americano, por sua vez, havia solicitado a seus aliados que o auxiliassem a evitar novos vazamentos além do que ocorrera em junho de 2013, quando Edward Snowden forneceu ao The Guardian, via Glenn Greenwald, informações que comprovavam a interceptação de ligações telefônicas e contas de internet para fins de investigação antiterrorismo, gerando, com isso, reações de repúdio a dita prática na comunidade internacional, inclusive da União Europeia e do Brasil, algo agravado na segunda metado do ano, quando novas revelações demonstraram que a prática se estendia inclusive sobre mensagens de chefes de Estado, dentre eles, as líderes alemã - Angela Merkel - e brasileira - Dilma Roussef.

Ao ser detido, David Miranda, relatou ter sido por diversas vezes ameaçado de prisão pelas autoridades policiais caso não entregasse as 
informações que presumivelmente estaria levando para o jornal The Guardian sobre práticas de investigação antiterrorismo. A polícia inglesa confiscou 9 itens: um laptop; um telefone celular; cartões de memória e DVDs.

Uma das garantias institucionais de limitação do poder de detenção e questionamento (stop-and-search) da autoridade policial na lei antiterrorismo inglesa é a de que, inexistindo fundado motivo para o interrogatório, este somente poderá ser realizado com a autorização específica do Secretário de Interior do governo - então, Theresa May -, que, em comentário publicado após o ocorrido com David Miranda, justificou seu ato sob a alegação de que, embora não houvesse suspeitas de que fosse um terrorista, ele estaria de posse de material ilegalmente subtraído de arquivos governamentais e que, se publicado, poderia facilitar práticas terroristas.

Os advogados de David Miranda e do The Guardian obtiveram um mandado judicial que suspendeu, provisoriamente, o poder das autoridades inglesas de analisarem, copiarem ou repassarem (inspecting, copying or sharing) o teor do que fora confiscado enquanto não fosse julgada a legalidade da atuação policial. O principal argumento jurídico dos advogados de David Miranda pela ilegalidade da atuação policial fora o de que os poderes de detenção e interrogatório do Terrorism Act 2000 inglês somente estariam de acordo com a política legislativa que os justificara se tais atos fossem voltados a determinar se David Miranda tinha filiação ao terrorismo; não, todavia, para o fim de apreensão das informações que ele carregava consigo.

Os efeitos no cenário político-jurídico brasileiro não tardaram a surgir para além da esperada indignação da União Europeia, Brasil e outros países. No Brasil, em 12 de setembro de 2013, a Presidência da República encaminhou a Mensagem 391/2013 à Câmara dos Deputados, solicitando a atribuição de regime de urgência constitucional, na forma do art. $64, \S 1^{\circ}$ da Constituição Federal de 1988, para a apreciação do Projeto de Lei ${ }^{\circ}$ 2.126/2011 (Marco Civil da Internet), que estabelecia princípios, garantias, direitos e deveres para o uso da internet no Brasil, abrindo-se o prazo de 45 dias para usa apreciação na Câmara dos Deputados e consequente sobrestamento de pauta a partir de 28 de outubro de 2013, projeto que ainda trancava a pauta da Câmara dos Deputados na segunda semana de dezembro 
de 2013, quando a prioridade acenada pelo presidente da Câmara era a aprovação da Lei Orçamentária de 2014, demonstrando a falta de consenso parlamentar sobre o teor do projeto. Finalmente aprovado na Câmara dos Deputados e encaminhado ao Senado Federal em março de 2014 sob o número PL 2.126/2011, ele sofreu tramitação acelerada aprovado em 22 de abril de 2014 no Senado, e sancionado pela Presidente da República durante a abertura do Encontro Global Multissetorial sobre o Futuro da Governança da Internet - NET Mundial, em 23 de abril de 2014.

A iniciativa presidencial de concentração de esforços na disciplina normativa de tecnologias da informação e comunicação para dificultar a invasão da privacidade por sistemas institucionais de varredura de ligações telefônicas e mensagens eletrônicas foi verbalizada em alto e bom tom na fala da presidente do Brasil na ONU, em setembro de 2013, com repercussão na mídia mundial. Em 4 de novembro de 2013, o Decreto presidencial $\mathrm{n}^{\circ} 8.135$ dispôs sobre a exigência de que as comunicações de dados da administração pública federal fossem realizadas por redes de telecomunicações e serviços de tecnologia da informação fornecidos por órgãos ou entidades da administração pública federal, incluindo empresas públicas e sociedades de economia mista da União e suas subsidiárias.

Talvez o efeito mais marcante da crise de invasão de privacidade, embora pouco divulgado, tenha sido o de abertura do canal de contratações diretas de serviços de tecnologia da informação por parte da União para entidades como a Telebras, o Serpro, a Dataprevi e a RNP: a qualificação da conexão dos órgãos do governo como estratégica pelo Conselho de Segurança Nacional, dispensando-se a licitação dos serviços. Essa solução desburocratizante dificilmente teria vindo à lume impune sem o auxílio da crise mundial de confiança gerada pelo uso de infraestrutura de pontos de contexão internacionais da internet e de empresas multinacionais de telecomunicações para os fins de investigação norte-americana.

O movimento brasileiro foi ombreado por manifestações globais contrárias ao aumento do poder de monitoramento da rede mundial de computadores por governos ao redor do mundo. Em carta aberta de dezembro de 2013, assinada pelas gigantes Google, Microsoft, Twitter, LinkedIn, Yahoo, Aol, Facebook e, parcialmente, Apple, intitulada Global Government Surveillance Reform, pediu-se, dentre outras coisas, o livre fluxo da informação, indo de encontro à proposta brasileira de exigência de 
instalação de servidores em solo brasileiro para guarda dos dados dos serviços da internet, bem como a limitação do monitoramento governamental das informações das redes por propósitos legais específicos. Dito documento também conclamou os Estados Unidos a tomar a liderança na reforma proposta, alertando para o fato de que as revelações de monitoramento das redes de internet e telefonia realizadas pelos Estados Unidos teria pendido o fiel da balança em favor dos Estados e em prejuízo dos direitos do indivíduo.

$\mathrm{Na}$ ONU, por sua vez, Alemanha e Brasil apresentaram projeto de resolução sobre o direito à privacidade na era digital ao final aprovado na III Comissão da $68^{\mathrm{a}}$ Assembleia Geral das Nações Unidas, classificando como atos altamente intrusivos os atos de vigilância ou interceptação ilícita de comunicações, como também a coleta arbitrária de dados pessoais. Democracia, privacidade e liberdade de expressão foram eleitos como pedras fundantes da proposta, que contou com 55 países copatrocinadores.

\section{Reestruturação da ANATEL}

Em termos de estruturação da agência reguladora, uma antiga demanda foi finalmente implementada via aprovação da Resolução da ANATEL $\mathrm{n}^{\circ}$ 612, de 29 de abrio de 2013, que, ao reeditar o Regulamento Interno da Agência, reequacionou sua estrutura orgânica para contemplar superintendências mais aderentes aos grandes temas regulatórios de: a) planejamento e regulamentação (SPR); b) outorgas e recursos à prestação (SOR); c) fiscalização (SFI); d) controle de obrigações (SCO); e) competição (SCP); f) relações com consumidores (SRC); g) gestão interna da informação (SGI); h) administração e finanças (SAF).

Em outra seara menos visível, o Conselho Diretor da ANATEL passou a publicar com ênfase as ementas das decisões sobre processos administrativos pré-selecionados em claro intuito de formatação de uma jurisprudência administrativa de índole regulatória.

A agenda regulatória aprovada pelo conselho diretor da ANATEL em agosto de 2013 tratou dos usuais suspeitos - ampliação de acesso, certificação, competição, consumidor, modelo de prestação, pesquisa e desenvolvimento, planejamento, qualidade e recursos escassos -, mas a ausência eloquente da prioridade de formação do regulador demonstrou que 
o movimento de reestruturação da Agência não tinha como foco principal a transformação atualizadora do próprio regulador.

\section{UIT um pouco mais pública}

Algo pouco conhecido mesmo por parte do público no setor de telecomunicações diz respeito ao formato de funcionamento da União Internacional de Telecomunicações, que, em grande medida, assemelha-se a uma associação privada ao gerir seus relatórios finais de conferências como produtos à venda para o público interessado.

A sessão de 2013 do Conselho da UIT alterou parcialmente os obstáculos ao acesso público à informação de tais reuniões ao aprovar uma contribuição da delegação brasileira, que propôs a gratuidade de acesso eletrônico dos relatórios finais das Conferências Mundiais de Desenvolvimento das Telecomunicações (UIT-D).

Em uma segunda contribuição brasileira também aprovada em 2013, instituiu-se o dever da UIT-D de divulgar informações de acompanhamento de projetos implementados, inclusive custeio e financiamento em claro movimento de expansão de responsabilidade gerencial e transparência daquele organismo internacional vinculado à Organização das Nações Unidas.

\section{Universalização celular para a zona rural}

O ano de 2013 também serviu de palco para o aumento das pressões de localidades não atendidas por cobertura celular para as pleitearem no Judiciário, embora sem êxito, à medida que as tentativas, usualmente via ações civis públicas interpostas pelos ministérios públicos estaduais, viram suas pretensões negadas por aplicação do princípio da deferência técnicoadministrativa do Judiciário às decisões regulatórias, que projetavam a cobertura das áreas rurais dentro de um raio de $30 \mathrm{~km}$ da sede municipal de $30 \%$ dos municípios atendidados até junho de 2014 e $100 \%$ até dezembro de 2015, segundo as regras do edital das faixas de 2,5 GHz e $450 \mathrm{MHz}$.

Como parcela das localidades em zona rural situa-se fora do raio de 30 km da sede municipal, em especial na Região Norte do país, em diversos momentos, o Ministro das Comunicações chamou à mesa de negociação às empresas vencedoras das licitações de $2,5 \mathrm{GHz}$ e $450 \mathrm{MHz}$ para conseguir a antecipação de metas de atendimento da zona rural e de ampliação para 
além dos $30 \mathrm{~km}$ de raio das sedes municipais. Cerca de 10 mil distritos não foram atingidos por tais metas de cobertura. Em meio às negociações, o Ministro das Comunicações acenou que em caso de não ser alcançado um acordo, o atendimento dos distritos não abrangidos nas metas de cobertura seria introduzido como obrigação dos vencedores da vindoura licitação da faixa de $700 \mathrm{MHz}$.

Tardou, mas a associação GSMA, que representa as operadoras móveis, apresentou estudo comparativo de 64 países, dos quais um terço não teriam desembolsado nenhum montante das contribuições coletadas a título de universalização das telecomunicações, computando o patrimônio acumulado de US\$ 11 bilhões. Com base no estudo, a GSMA conclamou os governos a implementarem "moratória imediata na coleta de mais recursos para fundos de serviço universal e a reconsiderarem suas futuras aplicações" com ênfase na tecnologia móvel.

\section{Controle social e político}

O Senado Federal aprovou em 27 de fevereiro de 2013, urgência na tramitação do Projeto de Resolução do Senado PRS 10/13, que introduziu a exigência de comparecimento dos dirigentes das agências reguladoras para prestação de contas em reuniões conjuntas de três comissões: a comissão específica relacionada à área da agência; a Comissão de Assuntos Econômicos (CAE); e a Comissão de Constituição, Justiça e Cidadania (CCJ). A Resolução n ${ }^{\circ}$ 4, de 2013, do Senado Federal, daí advinda alterou o Regimento Interno da Casa para disciplinar o comparecimento anual de dirigentes de agências reguladoras ao Senado Federal em franco movimento de retomada de rédeas do Congresso Nacional na fixação de rumos do modelo regulatório brasileiro.

Do lado do usuário/consumidor e cidadão, a institucionalização dos conselhos de usuários foi expandida em 2013, mediante Regulamento de Conselhos de Usuários aprovado pela Resolução da ANATEL n ${ }^{\circ}$ 623, de 18 de outubro de 2013, de exigência de conselhos de usuários, antes restritos à telefonia fixa concedida, para empresas de porte de TV por assinatura, telefonia móvel, serviço de comunicação multimídia (banda larga fixa) e serviço móvel especializado.

A desoneração tributária de smartphones, entretanto, passou ao largo da oitiva dos interessados diretos. A aposta de 2013 de atração de fabricantes 
de smartphones para o Brasil se concretizou via desoneração tributária do PIS/PASEP e da COFINS na fabricação de smartphones com valor de até $\mathrm{R} \$ 1,5$ mil classificados na posição 8517.12.31 da TIPI, que obedecessem aos requisitos técnicos constantes de portaria do Ministério das Comunicações, representando uma desoneração anunciada pela Teletime de 9,25\% do preço do aparelho no Brasil. Quando somada à desoneração de que gozam os smartphones produzidos no país que seguem os requisitos de processo produtivo básico (PPB), a desoneração pode alcançar $25 \%$ do preço do aparelho. Mas a política pública industrial de desoneração somente teve seus contornos definidos quando de sua regulação via portarias do Ministério das Comunicações, que estipularam as "características técnicas" mínimas para desoneração dos smartphones. Dentre as medidas, constaram exigências referentes ao equipamento em si, como também aos seus softwares e aplicativos, tais como: suporte à conexão padrão IEEE 802.11 (Wi-Fi); presença de aplicativo de navegação na rede mundial de computadores que permitisse o acesso a páginas padrão HTML; sistema operacional que disponibilizasse ferramentas de desenvolvimento de aplicativos por terceiros (SDK - Software Development Kit e API Application Programming Interface); tela sensível ao toque ou teclado físico completo; tela de entrada e saída de informações de área superior a $18 \mathrm{~cm}^{2}$; e pacote mínimo de aplicativos desenvolvidos no Brasil previamente embarcado. Para implementação deste último requisito, fora constituído um comitê tripartite formado por fabricantes de smartphones, operadoras móveis e representantes do governo federal, que estabeleceu diretrizes para o desenvolvimento dos aplicativos. Em antecipação sobre a posição ministerial em tal comitê, fora dito, à época, por fontes do Ministério das Comunicações, que seriam privilegiados aplicativos que "respond[essem] às necessidades brasileiras, e não apenas traduções de títulos de sucesso desenvolvidos em outros países".

Enquanto comitê de definição do direito de escolha ao acesso de aplicativos embarcados financiados por política governamental de desoneração tributária, é de se perguntar sobre a ausência eloquente de outros atores setoriais de representação social nessa etapa. Em nível de definição regulatória, a principal decisão quanto ao conteúdo embarcado ou canais embarcados de acesso a conteúdo fora relegada a um comitê de interesses exclusivamente empresariais e governamentais. A contar pelas 
manifestações favoráveis da indústria de smartphones - Nokia e Samsung manifestaram-se expressamente favoráveis ao embarque de aplicativos nacionais - e das empresas de telecomunicações em geral, o esforço governamental de desoneração tributária claramente agradou aos atores empresariais, tratando-se os consumidores e os cidadãos em geral como tutelados da díade Estado-Mercado.

\section{Competição e outros temas regulatórios}

No tocante à regulação de transações de atacado das telecomunicações, entrou em funcionamento o Sistema de Negociação das Ofertas de Atacado (SNOA), previsto no Plano Geral de Metas de Competição (PGMC), que passou a concentrar a negociação de atacado das telecomunicações, aplicável à exploração industrial de linha dedicada (EILD), contratação de torres de transmissão, entre outros elementos relevantes de atacado das telecomunicações. A tônica dos discursos justificadores do SNOA foi, à época, a da responsabilidade estatal em tornar o mercado de atacado um mercado civilizado.

Mas nem tudo resultou de avanço da regulação sobre o setor de telecomunicações. Em 8 agosto de 2013, a Superintendência de Outorga e Recursos à Prestação da ANATEL publicou a Portaria $n^{\circ}$ 639, de 25 de julho de 2013, disciplinando o Procedimento Simplificado de Outorgas (PSO) para autorizações simultâneas dos serviços de comunicação multimídia (SCM), fixo comutado (STFC) e de acesso condicionado (SeAC) com o custo unitário de $\mathrm{R} \$ 9$ mil; um passo histórico rumo à convergência de licenças.

O final do ano de 2013 presenciou a renovação dos esforços da ANATEL em implementar a migração de parcelas da faixa de frequência de $700 \mathrm{MHz}$ para os serviços móveis, mediante o início dos testes de convivência entre a radiodifusão - canais 38,48 e 51 - e as transmissões móveis de quarta geração LTE. Dentre os objetivos de tais testes, vislumbrava-se o de produzir regulamento para disciplina de mitigação de interferências prejudiciais entre a banda larga móvel e a radiodifusão.

O tema da expansão dos serviços móveis sobre espectro antes reservado à radiodifusão consolidou-se na agenda internacional, em que foi inserido como primeiro item de pauta da Conferência Internacional de Radiocomunicação da UIT de 2015, em Genebra, a identificação e 
atribuição de novas faixas de frequências para serviços móveis muito em virtude de lobby patrocinado pelos Estados Unidos e Canadá, cuja presença da TV aberta é historicamente pouco expressiva. A proposta de tais países para 2015 foi a de atribuição de certas faixas de radiofrequências para serviços móveis, inclusive a faixa de $470 \mathrm{MHz}$ a $698 \mathrm{MHz}$, ocupada pela TV digital após migração dos canais analógicos. Para esta faixa, a proposta foi de ocupação em caráter primário para ambos os serviços de radiodifusão e móveis. Assim, eventual interferência prejudicial dos serviços móveis na radiodifusão não se resolveria facilmente pela aplicação da regra de que serviços de caráter secundário devem cessar a interferência prejudicial sobre serviços de caráter primário.

Em oposição ao movimento de países capitaneados pelos Estados Unidos, o Brasil obteve posicionamento favorável da reunião preparatória da CITEL para a Conferência da UIT sobre sua proposta contrária à atribuição da faixa de TV digital para serviços móveis, alcançando o status de proposta interamericana (IAP - Interamerican Proposal).

$\mathrm{Na}$ fronteira das faixas destinadas à radiodifusão digital e aos serviços móveis, há um ator inusitado estrategicamente ali inserido: as forças de segurança nacional. Ao se destinar espectro da faixa de $700 \mathrm{MHz}$ para serviços móveis, a ANATEL também satisfez pleito das forças de segurança nacional por espaço exclusivo nesta faixa. Elas receberam uma faixa de 5 $\mathrm{MHz}+5 \mathrm{MHz}$ localizado imediatamente acima do último canal de radiodifusão, apostando a ANATEL na baixa densidade de estações radiobase (ERBs) do Exército para facilitar a acomodação de radiodifusão e serviços móveis em faixas próximas.

A disputa pelo espectro da TV digital também chamou a atenção de produtores de microfones e monitores sem fio que operam na frequência de $600 \mathrm{MHz}$ e que poderiam ser inviabilizados com o ingresso dos serviços móveis. Em novembro de 2013, a fabricante de equipamentos Sennheiser ingressou com processo perante o órgão regulador norte-americano solicitando garantias de que o leilão previsto para 2014 para serviços móveis naquele país não inviabilizasse o uso de equipamentos em espetáculos públicos, ou que os vencedores do leilão indenizassem os fabricantes e usuários de equipamentos inutilizados pelo seu ingresso na frequência de $600 \mathrm{MHz}$, haja vista a experiência semelhante de prejuízos não indenizados ocorridos com a ocupação da faixa de 700 MHz em 2008. 
Enfim, o que se pediu foi que o custo de realocação dos equipamentos para a faixa de $500 \mathrm{MHz}$ fosse arcado pelas empresas beneficiárias da liberação da faixa de $600 \mathrm{MHz}$ para serviços móveis. Para o cenário em que a União Internacional de Telecomunicações recomenda $1.300 \mathrm{MHz}$ destinados a serviços de telefonia móvel em 2015 em contraposição à média de $263 \mathrm{MHz}$ e $574 \mathrm{MHz}$ de frequências destinadas a tais serviços na América Latina e no Brasil respectivamente, é visível como a pressão por expansão da banda larga móvel dominará as políticas públicas e a regulação do setor no Brasil nos próximos anos.

Por detrás de todas as idas e vindas de atribuição e destinação de espectro nas faixas de $470 \mathrm{MHz}$ e $698 \mathrm{MHz}$ está uma opção regulatória por espaço para evolução tecnológica de dados e mídia, em que a previsão de frequências adicionais é antecipada frente às previsões de demanda para serviços móveis de banda larga cada vez mais larga de um lado, e radiodifusão com cada vez mais resolução e poder de transmissão de dados, de outro. Em pronunciamento na International Broadcasting Convention (IBC) de 2013, em Amsterdã, a diretora de distribuição da BBC de Londres ressaltou a necessidade de que parte da faixa de $700 \mathrm{MHz}$ permanecesse com as radiodifusoras para permitir a evolução tecnológica do serviço, em especial, em virtude da maior eficiência da transmissão radiodifusora em quantidade de dados transitados em face das transmissões móveis de banda larga.

O projeto de Lei das Antenas (PL 5.013/2013) tão desejado pelas empresas para uniformizar as regras de instalação de antenas no complexo sistema federativo de disciplina jurídica municipal de posturas urbanas foi passado para o ano de 2014 com projeção de devolução ao Senado Federal para pronunciamento sobre pontos alterados na Câmara dos Deputados.

Até aqui, nenhuma surpresa na ênfase na atribuição da faixa de $700 \mathrm{MHz}$ a serviços móveis e na lenta tramitação de projeto de lei que, embora muito desejado, esbarra na questão de divisão de competências federativas. A surpresa de final de ano ocorreu por força de decisão do Conselho Administrativo de Defesa Econômica (CADE), que se manifestou contrariamente à participação da Telefónica na Vivo, via aquisição de participação da Portugal Telecom, se mantida a participação indireta da Telefónica na TIM Brasil, por intermédio do consórcio Telco, controlador da Telecom Itália com então $22,4 \%$ das ações ordinárias. O movimento de 
consolidações do setor no Brasil parece ter chegado ao seu limite, na sinalização da agência antitruste brasileira.

O ano de 2013 foi encerrado com uma consulta pública da ANATEL destinada a colher contribuições da sociedade para a penúltima revisão quinquenal dos contratos de concessão antes do seu termo final em 2025. Ao introduzir o rol de 31 perguntas à sociedade divididas entre os temas de universalização, TUP, qualidade, seguro-garantia, LDN, e oferta e cobrança, a consulta pública acenou com a extinção do regime público para o serviço de telefonia fixa, sob o argumento de que haveria um descompasso entre os objetivos desse regime rumo à universalização e continuidade e os efeitos práticos de desincentivo a investimentos.

A indicação do entendimento da ANATEL inscrita na abertura das questões dessa consulta pública evidencia o ponto de vista da Agência de que o regime público se definiria por suas consequências - universalização e continuidade - ao invés de se definir por sua essência - serviço essencial. A lógica da essencialidade do serviço, que é a razão constitucional dos deveres de universalização - direito de todos - e continuidade do serviço responsabilidade estatal - passou ao largo da consulta, que concentrou sua atenção na atratividade econômica do serviço de telefonia fixa. Portanto, a Agência tem tratado da questão do regime público não por sua principiologia, mas por um de seus efeitos periféricos de atratividade mercadológica do serviço concedido.

Encerra-se este relato também com uma $32^{\mathrm{a}}$ pergunta: a ANATEL vê sua função reguladora central como promoção de atratividade dos serviços ou de proteção dos direitos fundamentais? A consulta pública que encerrou o ano de 2013 responde essa pergunta com a primeira hipótese, mas isso nega toda a justificativa principiológica de um Estado Regulador, que apoia o modelo regulatório de agências autônomas na preservação de direitos via regulação de mercados; não no inverso.

O Conselho Editorial 
